\title{
Risk Factors for Adverse Outcome for Elderly Patients undergoing Curative Oncological Resection for Gastrointestinal Malignancies
}

\author{
Yukai K. Lim ${ }^{a}$ Christopher Jacksona,b,c Emilia L. Dauway d,e Konrad Klaus Richter ${ }^{\mathrm{f}, \mathrm{g}}$ \\ a Southern District Health Board, Invercargill, New Zealand; \\ b University of Otago, Dunedin, New Zealand; \\ ${ }^{c}$ Cancer Society of New Zealand, Wellington, New Zealand; \\ dSchool of Medicine, University of Queensland, Brisbane, QLD, Australia;

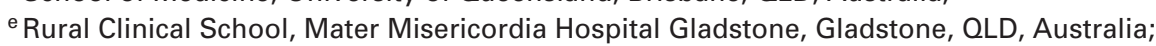 \\ ${ }^{f}$ Department of Surgery, Southland Hospital, Invercargill, New Zealand; \\ g Dunedin Hospital and School of Medicine, Dunedin, New Zealand
}

\author{
Keywords \\ Elderly · Octogenarian · Geriatric . \\ Gastrointestinal cancer · Complications
}

\section{Summary}

Background: The incidence of gastrointestinal cancer increases with age, with approximately $20 \%$ of these cases in people over 80 years of age. Due to pre-existing comorbidities, this onco-geriatric population often presents diagnostic and therapeutic challenges. Methods: A systematic review of articles on PubMed was performed to determine the predictive ability of screening tools and their components regarding the occurrence of adverse outcomes in elderly onco-surgical patients with gastrointestinal malignancies. Results: Surgical procedures in this patient cohort, particularly complex resections, may result in increased morbidity and mortality. The decision to treat an elderly patient with curative intent requires sound clinical judgment based on knowledge, consideration of objective parameters, and experience. These patients could potentially be optimized for surgery with the improvement of nutritional and overall performance status as well as with stabilizing comorbidities. Conclusion: Various geriatric assessment and screening tools have been developed to identify risk factors to assist the surgeon and the interdisciplinary team in treatment planning, including the Frailty Assessment Score, Timed Up and Go test, nutritional status, and Activities of Daily Living test. It is important to emphasize that transparent and open communication between the treating surgeon and the patient is crucial in that the patient fully understands the implications of the treatment plan.

(c) 2017 S. Karger GmbH, Freiburg

\section{Introduction}

Gastrointestinal cancer is increasingly a disease of the elderly, considering the aging general population and the accumulation of genetic damage over time. The incidence rate for a patient older than 65 years of age is increasing rapidly, and demographic projections suggest that the number of persons 65 years and older in the USA will double from the current estimate of 35 million persons to a projected 70 million by 2030 [1]. Median ages for cancer patients at death for both males and females for pancreatic, stomach and colorectal cancers range from 71 to 77 years [2]. Surgical resection continues to be the only curative option for patients with localized and locoregional gastrointestinal malignancy. Although postoperative complications remain higher in the elderly population compared to younger cohorts, age alone cannot be used as a criterion. People of similar ages may experience differences in physical health, medical problems, neurodegenerative diseases, and mental health. Despite increasing evidence that elderly patients have similar survival rates as their younger counterparts after oncological operations, studies have shown that based on age, standard oncologic care is not offered to the geriatric population [3]. Allowing

\section{KARGER}

() 2017 S. Karger GmbH, Freiburg 
for selection bias in reported series, oncologic operations particularly for oesophageal cancer [4], gastric cancer [5], and colorectal cancer [6] have similar outcomes regardless of age. Therefore, age alone should not be considered a determining feature in selecting a treatment plan for a particular patient. The onco-geriatric patient's care should be a collaboration of an interdisciplinary team including the surgical oncologist, medical and radiation oncologist, geriatrician, psychologist, and other allied-health staff. The multidisciplinary team provides a holistic approach to optimize medical care for the patient's journey, including oncologic surgery as often the only chance for cure.

\section{Screening Tools}

Preoperative screening tools have been developed to better identify patients with poorer physiological reserves and higher surgical risk. Currently, it is understood that the older population should not be assessed on chronologic age, but rather frailty, functionality, and dependency $[7,8]$. The International Society of Geriatric Oncology (SIOG) task force has recommended a Comprehensive Geriatric Assessment (CGA) along with several other screening tools for evaluating an elderly patient for surgery $[9,10]$. These evaluations have been shown to be predictive of adverse outcomes after an oncological operation in an elderly patient. It is recommended to use these assessments before the operation to identify those frail patients and to guide treatment [11]. However, there is no consensus on the best screening tool to use for assessment. Hence, most assessments are made up of different modalities such as functional status, nutritional status, mood and emotional status, as well as cognition, comorbidity, polypharmacy, and frailty to provide a more comprehensive assessment of an elderly patient prior to surgery. Validated screening tests or measurements include:

- Activities of Daily Living (ADL) and Instrumental Activities of Daily Living (IADL) comprise a scoring system based on the ability to perform self-care tasks and activities of basic functioning, respectively, i.e. shopping, housework, and preparing meals. These scores measure functional status.

- The American Society of Anesthesiologists (ASA) score is a commonly used tool by the anaesthetist to measure the physical status of patients prior to surgery.

- Timed Up and Go (TUG) is a test that reliably assesses an individual's mobility and balance. It measures the time a person takes to rise from a chair, walk 3 meters, turn around, walk back to the chair, and sit down. Having a time greater than $12 \mathrm{~s}$ has been associated with impaired mobility and predisposition to falls [12, 13].

- Vulnerable Elders Survey-13 (VES-13) [14] is a functionbased 10-point scoring system where a higher score identifies vulnerable patients. The survey includes age, personal gauge of health, the ability to perform physical activity, and fundamental activities. A higher score has been shown to strongly predict death and functional decline [15].
- The Global Fatigue Index (GFI) is derived from a multidimensional assessment of fatigue which measures fatigue across four dimensions, i.e. severity, distress, impact of fatigue on various ADL, and timing of fatigue. Scores range from 1 to 50 (severe fatigue).

- The ECOG performance status score developed by the Eastern Cooperative Oncology Group is a 5-grade score used to measure a patient's functional status according to their level of activity.

- Mini-mental state examination (MMSE) is a 30-point scoring system that measures cognition by examining orientation, recall, language abilities, attention, calculation, and visuospatial ability. A lower score indicates a lower cognition.

- The Geriatric Depression Scale (GDS) is a 15-item (short) or 30 -item (long) questionnaire that measures the mood of an elderly patient [16].

- The Brief Fatigue Inventory (BFI) is a rapid assessment tool to assess the severity and impact of cancer-related fatigue on daily functioning.

- Nutritional Risk Score (NRS) or Mini Nutritional Assessment (MNA) are used to identify patients that are at risk of undernutrition or malnourishment.

- Fried Frailty Index [17]: Its components include weight loss in the previous year, grip strength, exhaustion, low physical activity, and slowed walking. One point each is given for every component, with scores from 2 to 3 points indicating moderate frailty and 5 points suggesting significant frailty.

- The CGA score is also used as a marker of frailty.

\section{Review}

\section{Methods}

The systematic review of articles on PubMed was performed by two of the authors (YKL, KKR). Its aim was to determine the predictive ability of screening tools and their components regarding the occurrence of adverse outcomes in elderly onco-surgical patients with gastrointestinal malignancies, i.e. gastric cancers, hepatobiliary cancer, pancreatic cancers, and colorectal cancers. The aim was to identify risk factors, appropriate measures, and assessments which can be implemented to predict outcomes in these complex patients. The search strategy involved using the following keywords either individually or in combination: 'elderly', 'octogenarian', 'geriatric', 'aged', 'gastrointestinal', 'colorectal', 'gastric', 'cancer', 'neoplasm', 'malignancy', 'risk factors', 'predictors', 'outcomes after surgery', 'morbidity', 'mortality', 'complications', and 'adverse outcomes' (see also search string, available as supplementary material at http://www.karger.com/ProdukteDB/produkte. asp?doi=475938). Initially, a general exclusion of low-yield articles through the PubMed filter system was performed. Papers that did not include or defined elderly patients, using an age more than 65 years were excluded. Review articles were also excluded as there is a significant number of duplicates of studies in the literature that 
have been reviewed. They were, however, used to source further relevant articles. Only articles published since the millennium were included to establish currency and validity of modern practice. Subsequently, full-text articles were selected based on the following inclusion criteria: studies that focused and included older patients $>65$ years, diagnosis of primary gastrointestinal malignancies, predictors of adverse outcomes, and screening tools. Articles excluded were those in which surgery was not the primary intervention (e.g. treatment with chemotherapy), secondary gastrointestinal malignancies (e.g. metastases from breast or lung cancer), and duplicate studies. Selected articles were then reviewed and chosen based on agreement and consensus from both investigators (supplementary table, available at http://www.karger.com/ProdukteDB/produkte. asp?doi=475938). Data extraction was performed on the selected articles examining various known risk factors, scoring tools and frailty scores, biochemical markers, use of CGA, and listed comorbidities for elderly surgical patients. Outcomes collected were morbidity data based on Clavien-Dindo, the National Surgical Quality Improvement Program (NSQIP) classification, length of stay, and mortality. Forest plots were drawn based on each outcome with the available information, with $95 \%$ confidence interval and $\mathrm{p}$-value displayed when available on GraphPad. The weighted value of the population percentage was included. Due to the significant heterogeneity of the data from individual studies, meta-analyses were not able to be performed.

\section{Results}

The literature review was performed in March 2017 and yielded 15,320 records. A total of 2,755 abstracts was assessed for relevance with exclusion criteria applied. Ten studies were ultimately included for qualitative analysis based on the above criteria that were specified after consensus from both investigators. The ten studies consist of nine prospective and one retrospective cohort study (fig. 1), and the results of each test or predictor of outcome modality were plotted on Forest plots (fig. 2-4).

\section{Frailty}

Frailty, as measured using the Fried and Hopkins Frailty Scores, showed a correlation between increasing frailty scores and the likelihood of postoperative complications, the length of hospital stay, and the likelihood of discharge to an assisted living care facility [18-20]. Kristjansson et al. [21] used components of a CGA that covered Personal Activities of Daily Living (PADL) $<19$, IADL $>43$, comorbidity assessment, polypharmacy, MNA, MMSE $<24$, and GDS $<13$. A patient with one of these criteria was considered in the 'frail' category. Those having neither criteria were placed in the intermediate category. Frail patients on multivariate analysis were shown to be three times more likely to develop severe complications (odds ratio (OR): 3.13). In comparison to the non-frail patients, the relative risk of being frail and of having any complication or severe complications was 1.59 and 1.75 , respectively.

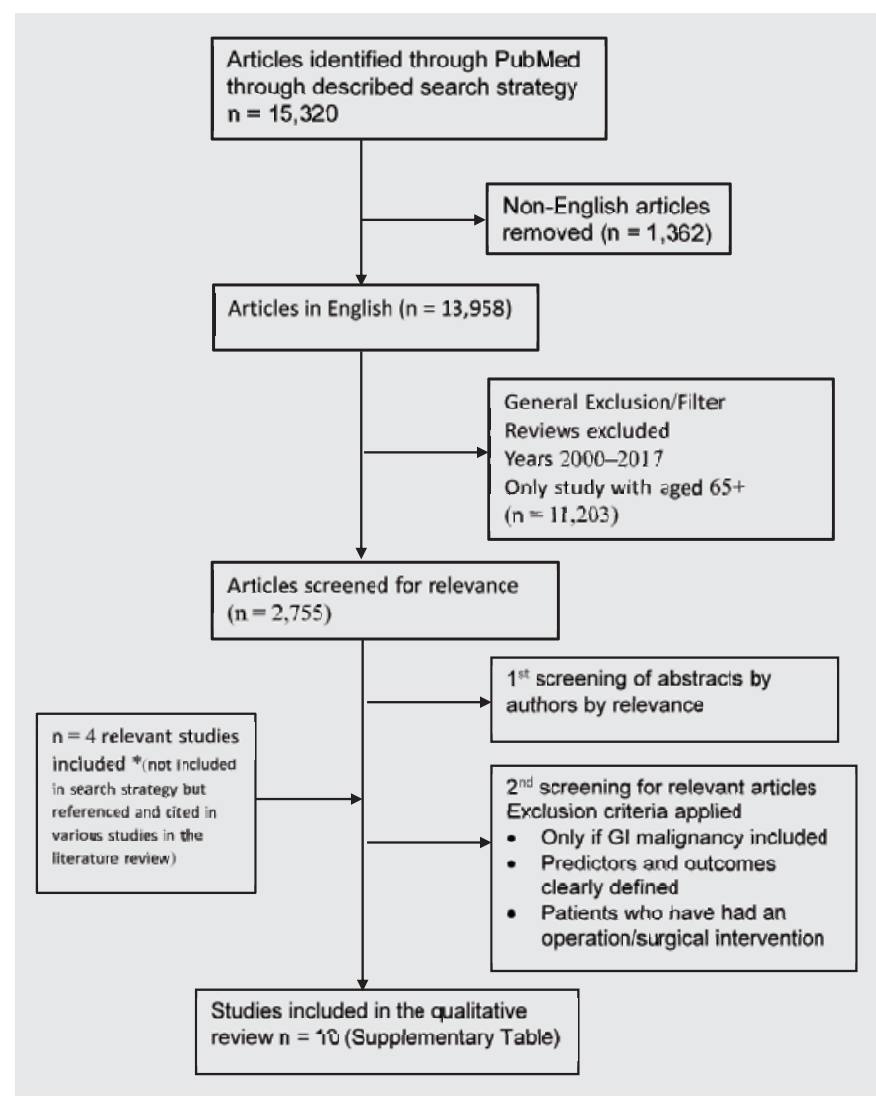

Fig. 1. Flow diagram detailing the review process.

\section{Haemoglobin}

A haemoglobin level of less than $10 \mathrm{~g} / \mathrm{dl}$ preoperatively (hazard ratio: 6.21-7.56) was shown to be predictive of a Clavien-Dindo complication [22]. On the contrary, a preoperative haemoglobin level of more than $10 \mathrm{~g} / \mathrm{dl}$ was shown to be protective (OR: 0.84 ) [19]. Interestingly, a haemoglobin level $<12 \mathrm{~g} / \mathrm{dl}$ was not significant in another study [23].

\section{ASA}

Two studies $[20,21]$ demonstrated that an ASA score $>3$ was not significantly predictive of complications as defined by the Clavien-Dindo I-IV complications; whereas, four other studies showed that having an ASA score $>2$ was predictive [22-25]. Of the two studies with 30-day mortality as an outcome, scoring ASA $>2$ was the only predictor that was significantly associated with increased 30-day mortality [22, 26].

\section{Timed Up and Go}

The TUG score was described by Huisman et al. [23] to be highly predictive of adverse outcomes. In these studies, patients having a TUG time of more than $20 \mathrm{~s}$ were four times more likely to have any of Clavien-Dindo I-IV complications postoperatively. It was also noted that in combination with having an ASA score $>2$, elderly patients were shown to be 29 times more likely to develop complications. 


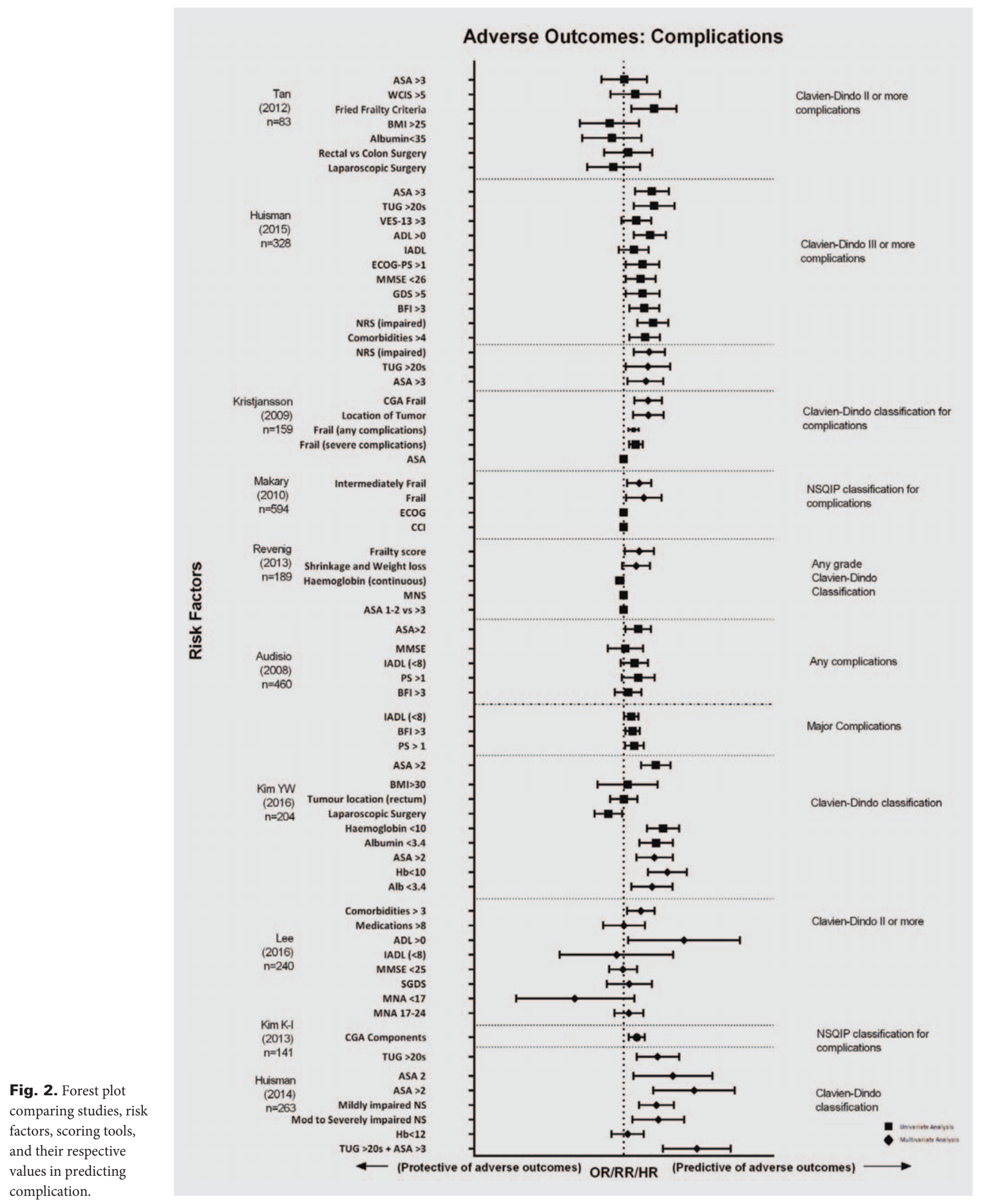




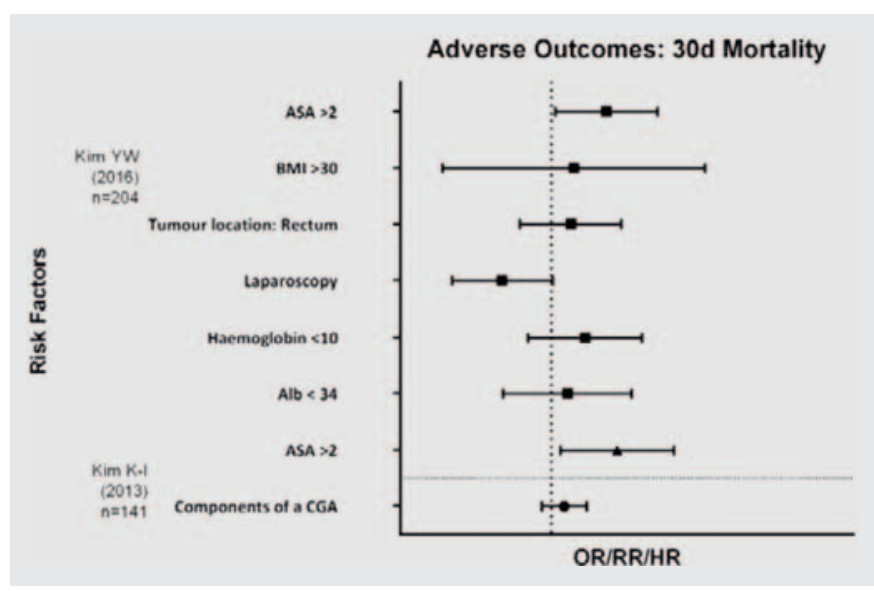

Fig. 3. Risk factors and their predictability.

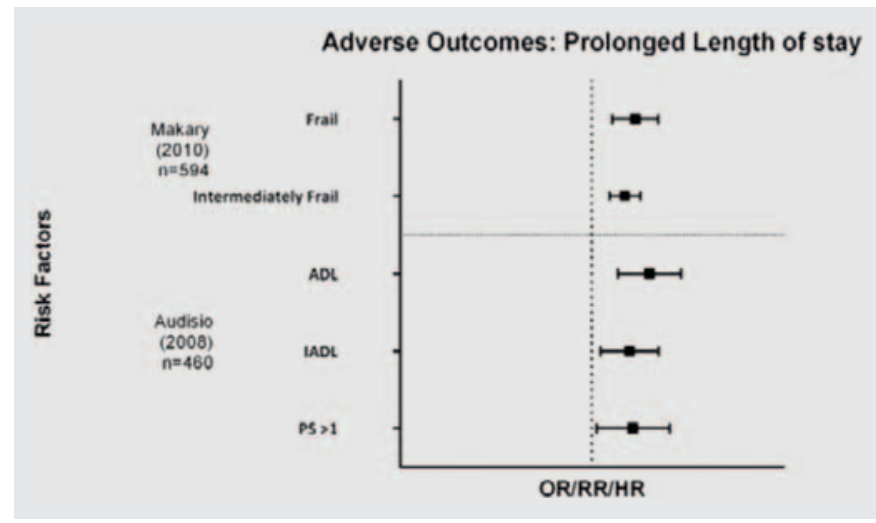

Fig. 4. Association of risk factors and length of stay.

\section{Type of Surgery}

Compared to open surgery, laparoscopic surgery was well tolerated and found to be significantly protective, with patients half as likely to develop Clavien-Dindo II complications (OR: 0.49) [22] Tan et al. [20] showed similar results (OR: 0.625). However, it was not statistically significant. Both studies used univariate analyses and involved only colorectal patients.

\section{Nutritional Status}

Huisman et al. $[23,27]$ demonstrated that having an impaired nutritional status predicted complications, particularly in elderly patients with moderate to severe impaired nutritional status. However, this was not shown when using an MNA [28].

\section{Dependency and Function}

Dependency and function assessment predictors adopted in these studies showed varying results in predicting adverse outcomes. Dichotomous classifications were given to scoring systems as none or all. An ADL score $>0$ indicating some form of dependency was shown to be predictive in two studies [25]. An IADL score $<8$ was not a significant predictor of the primary adverse outcomes in the studies reviewed $[24,25]$. However, when 'any complication' was looked at as an outcome, it could be demonstrated that an IADL score of $<8$ made an individual $40 \%$ more likely to have an adverse outcome $(\mathrm{OR}=1.43)$. Huisman et al. [25] showed that an ECOG performance status $>1$ was a significant predictor, but this was not validated by others [24].

\section{Length of Hospital Stay}

Tests that were predictive of an increased length of stay were reviewed in two studies $[18,24]$. According to Fried's criteria, being intermediate or frail $(\mathrm{ADL}>0, \mathrm{IADL}<8)$ and an ECOG performance status $>1$ were all predictive of a prolonged length of stay in the hospital.

\section{Discussion}

In clinical practice, gastrointestinal malignancies are a diverse group of clinical entities with varying degrees of physiologic stress and significant variation in operative approach. This review attempted to include and assess all gastrointestinal malignancies as a single entity and highlight risk factors that were predictive of adverse outcomes. The differentiation of individual cancer types was avoided to provide a broader overview of this topic. This review evaluates several factors associated with adverse outcomes in elderly patients with gastrointestinal malignancy. Independent of age, factors including functional status, cognition, depression, nutritional status, mobility, and ASA score are strongly associated with adverse postsurgical outcomes. Screening tools available can be incorporated into the preoperative evaluation of the surgical practice to mitigate complications. Although assessment tools are clearly not an alternative to sound clinical judgment of the surgeon, or honest communication with the patient, there is a growing body of evidence supporting the necessity to use objective scores $[9,10]$. However, thus far it has been shown that the use of screening tools has not been widely adopted by surgeons [29].

Frailty as a measurement does not have an agreed-upon definition. Furthermore, scoring validity is often difficult to determine because of different components that measure an elderly patient's overall health, accurate physiologic reserve, and likelihood to thrive after an operation. Four of the presented studies incorporated and used frailty scores to improve quantification. All scores used were at least predictive of adverse effects in elderly and had a role in assisting the surgeon in the decision making. The review was limited by heterogeneity, used to define age range of the elderly, predictive factors, and the outcomes measured by the various assessments. Most variables were assessed dichotomously and not as a spectrum as intended by different scoring systems. The potential to exclude the 'intermediate-frail' patient creates bias. Most analyses performed were univariate analyses that could potentially miss or mask confounders, particularly when models consisting of different variables were used. Most scores such as dependency scores, MMSE, comorbidities, and depression scales have shown a general trend towards predicting the poor outcome but demonstrate variable significance. The use of these tools will vary according to the available resources of the institution, but 
many can be integrated into most settings. Initially, simple tests such as the TUG test and the ASA score could be easily incorporated by the surgeon; however, the benefits and limitations of each tool should be understood. These tests are predictive of poor outcomes and could be integrated into the preoperative workup of these patients [23]. Routine preoperative blood panels should be included to determine the predictive haemoglobin level of $<10 \mathrm{~g} / \mathrm{dl}$. Cardiopulmonary exercise testing (CPET) is a novel strategy to assess cardiopulmonary reserves before surgery. The idea is to replicate the stress a patient may experience during surgery to determine suitability for the operation. Moyes et al. [30] and Yanni et al. [31] have shown that upper gastrointestinal surgery for patients and an anaerobic threshold $<11 \mathrm{ml} / \mathrm{min} / \mathrm{kg}$ were associated with the development of cardiopulmonary complications and a trend towards a higher unplanned rate of intensive care admission. Although resource-intensive, CPET could be an additional test in quantifying cardiopulmonary reserves in elderly patients [30, 32] Several modifiable risk factors included in geriatric assessments have been shown to be predictive of poor outcome [25]. Nutritional status, physical activity, and muscle conditioning are areas in which the interdisciplinary team can prepare and improve the patient's condition before surgery. Also, the recent concept of prehabilitation - defined as the enhancement of the preoperative condition - has shown some benefits in reducing postoperative morbidity in patients while lowering costs [33-37]. However, this was not confirmed in all studies [38]. There is still controversy whether efforts to improve nutritional, modifiable risk factors and functional status preoperatively should be a priority or whether it rather delays surgical intervention and earlier definitive surgical management to remove the underlying cause of disease and suffering. Commonly, the elderly patient tends to have reduced functional residual capacity, increasing the risk of pulmonary complications. Pre-habilitation has had a substantial effect in decreasing pulmonary complications and improving functional residual capacity, in comparison to the traditional postoperative deep breathing and incentive spirometry programme. Therefore, conceptually, prehabilitation in reducing pulmonary complications is attractive.

The influence and underlying dynamics of differing health systems, cultures, philosophies, and economies to the cancer treatment of elderly patients have to be acknowledged. Incentives and deterrents of a health system invariably affect and influence surgical judgment. Social systems where resources are rationed (tax money-funded public health system) adopt cost-benefit models to favour the majority of the population, compared to a private system where performance correlates to financial gain. For example, in a country such as Germany where hospitals get financially better reimbursed the more surgical procedures are performed, the incentive for the whole team including the head of the department is to have a lower threshold to operate even on older frailer cancer patients. In contrast, the opposite is the case in a tax payer-funded health system where the whole incentive is to save as much money possible, even more so on elderly cancer patients with an uncertain outcome. In countries such as England or New Zealand, for example, the threshold to operate elderly cancer patients may be higher compared to countries such as France and Germany. Different motivating forces within the health system, i.e. tax-based financing for health systems/NHS (National Health Service)/private sector versus ring-fenced 'social contributions' taxation backed by private medical insurance with speedy access to care and virtually eradicated waiting lists, may be responsible. Also, high-volume metropolitan hospitals tend to perform higher risk procedures compared to rural community hospitals, regardless of the experience of the surgeon, as the tolerance of similar surgical complications is greater, and the individual surgeon remains more anonymous in a bigger centre compared to a small community hospital. Naturally, the health system where the cancer surgeon received his training may influence his decision making even when he chooses to work in a different cultural setting. The surgeon should be mindful of these influences and underlying forces.

The importance of 'years of life lost or gained' for the operation is significantly highlighted in studies. As a result of the shorter life expectancy of the elderly, overall survival is reduced compared to their younger counterparts [39]. The common perspective regarding intervention is to consider the risks and benefits of the suggested operation to preserve a quality of life and to improve survival. In a study of 31,574 patients, $80 \%$ of whom had a colectomy, factors to be most predictive of non-operative management included older age, black race, more hospital admissions, use of home oxygen, use of a wheelchair, being frail, and having dementia [40]. It concluded that the majority of older patients with colon cancer treated surgically had improved outcomes compared with non-operative management. Since many patients who were not selected for surgery died of unrelated causes, it was suggested that the surgical selection process was reasonable. The biologics of cancer in the elderly is an area that may show promise in providing more information as to the cancers we should be operating. Understanding whether they metastasize late or rather grow locally, or whether they have worse outcomes than poorly differentiated and mucinous carcinomas as compared to young patients would offer the clinician more information to guide management. For example, the currently widely available molecular, microsatellite and RAS testing for colorectal cancer in the elderly patient may be a way to understand the cancer biology better and allow for optimal wellinformed treatment choices [41].

Unfortunately, gastrointestinal malignancies often present with late-stage life-threatening symptoms such as bleeding or obstruction of abdominal viscera. Many of the available assessment tools in this context may be of limited value in an emergency setting. The decision to operate at all or adopt a palliative approach is particularly complex in these acute circumstances. Rudolf Nissen, one of the fathers of modern surgery, is quoted in saying at the end of his career in the 1950s: 'I believe that more misfortune arises through omission or hesitation in ... surgery than through operative complications' [42]. Nissen's statement highlights the importance of the surgeon's role in an honest and sensible communication with the patient and the family who will more often than less follow his or her advice as long as they developed trust and respect for their doctor. 


\section{Conclusion}

This review discussed current risk factors and predictors of adverse outcomes and surgical complications in onco-geriatric patients with gastrointestinal malignancies. Frailty assessment scores and other basic screening tools should be combined with the surgeon's experience and practical judgment to select the right patient for the best surgical procedure. An interdisciplinary approach in collaboration with a geriatric specialist to manage complex elderly patient and surgical treatment planning may improve clinic outcomes. Further research and studies should identify the optimal combination of tools that best predicts surgical success or failure. The role of the treating surgical oncologist in the communication process with the patient and the family, including his/her surgical and cultural background, must not be underestimated for decisions that ensure optimal treatment.

\section{Disclsosure Statement}

KKR: No conflict of interest. YKL, CJ, ELD: The authors did not provide a conflict of interest statement.

\section{References}

1 Yancik R, Ries LA: Cancer in older persons. Magnitude of the problem - how do we apply what we know? Cancer 1994;74:1995-2003.

2 Yancik R: Population aging and cancer: a cross-national concern. Cancer J 2005;11:437-441.

3 De Angelis R, Sant M, Coleman MP, Francisci S, Bail P, Pierannunzio D, Trama A, Visser O, Brenner H, Ardanaz E, Bielska-Lasota M, Engholm G, Nennecke A, Siesling S, Berrino F, Capocaccia R: Cancer survival in Europe 1999-2007 by country and age: results of EUROCARE-5 - a population-based study. Lancet Oncol 2014;15:23-34.

4 Tapias LF, Muniappan A, Wright CD, Gaissert HA, Wain JC, Morse CR, Donahue DM, Mathisen DJ, Lanuti M: Short- and long-term outcomes after esophagectomy for cancer in elderly patients. Ann Thorac Surg 2013;95:1741-1748.

5 Pisanu A, Montisci A, Piu S, Uccheddu A: Curative surgery for gastric cancer in the elderly: treatment decisions, surgical morbidity, mortality, prognosis and quality of life. Tumori 2007;93:478-484.

6 Ugolini G, Pasini F, Ghignone F, Zattoni D, Bacchi Reggiani ML, Parlanti D, Montroni I: How to select elderly colorectal cancer patients for surgery: a pilot study in an Italian academic medical center. Cancer Biol Med 2015;12:302-307.

7 Audisio RA, Cazzaniga M, Robertson C, Veronesi P Andreoni B, Aapro MS: Elective surgery for colorectal cancer in the aged: a clinical-economical evaluation. $\mathrm{Br}$ J Cancer 1997;76:382-384

8 Audisio RA, Veronesi P, Ferrario L, Cipolla C, Andreoni B, Aapro M: Elective surgery for gastrointestinal tumours in the elderly. Ann Oncol 1997;8:317-326.

9 Wildiers H, Heeren P, Puts M, Topinkova E, JanssenHeijnen ML, Extermann M, Falandry C, Artz A, Brain E, Colloca G, Flamaing J, Karnakis T, Kenis C, Audisio RA, Mohile S, Repetto L, Van Leeuwen B, Milisen K, Hurria A: International Society of Geriatric Oncology consensus on geriatric assessment in older patients with cancer. J Clin Oncol 2014;32:2595-2603.

10 Papamichael D, Audisio RA, Glimelius B, de Gramont A, Glynne-Jones R, Haller D, Kohne CH, Rostoft S, Lemmens V, Mitry E, Rutten H, Sargent D, Sastre J, Seymour M, Starling N, Van Cutsem E, Aapro M: Treatment of colorectal cancer in older patients: International Society of Geriatric Oncology (SIOG) consensus recommendations 2013. Ann Oncol 2015;26:463-476.

11 Caillet P, Canoui-Poitrine F, Vouriot J, Berle M, Reinald N, Krypciak S, Bastuji-Garin S, Culine S, Paillaud $\mathrm{E}$ : Comprehensive geriatric assessment in the decisionmaking process in elderly patients with cancer: ELCAPA study. J Clin Oncol 2011;29:3636-3642.
12 Verweij NM, Schiphorst AH, Pronk A, van den Bos F, Hamaker ME: Physical performance measures for predicting outcome in cancer patients: a systematic review. Acta Oncol 2016;55:1386-1391.

13 Wildes TM, Depp B, Colditz G, Stark S: Fall-risk prediction in older adults with cancer: an unmet need. Support Care Cancer 2016;24:3681-3684.

14 Saliba D, Elliott M, Rubenstein LZ, Solomon DH, Young RT, Kamberg CJ, Roth C, MacLean CH, Shekelle PG, Sloss EM, Wenger NS: The Vulnerable Elders Survey: a tool for identifying vulnerable older people in the community. J Am Geriatr Soc 2001;49:1691-1699.

15 Min L, Yoon W, Mariano J, Wenger NS, Elliott MN Kamberg C, Saliba D: The Vulnerable Elders-13 Survey predicts 5-year functional decline and mortality outcomes in older ambulatory care patients. J Am Geriatr Soc 2009;57:2070-2076.

16 Yesavage JA, Brink TL, Rose TL, Lum O, Huang V, Adey M, Leirer VO: Development and validation of a geriatric depression screening scale: a preliminary report. J Psychiatr Res 1982;17:37-49.

17 Revenig LM, Canter DJ, Kim S, Liu Y, Sweeney JF, Sarmiento JM, Kooby DA, Maithel SK, Hill LL, Master VA, Ogan K: Report of a simplified frailty score predictive of short-term postoperative morbidity and mortality. J Am Coll Surg 2015;220:904-911.e901.

18 Makary MA, Segev DL, Pronovost PJ, Syin D, Bandeen-Roche K, Patel P, Takenaga R, Devgan L, Holzmueller CG, Tian J, Fried LP: Frailty as a predictor of surgical outcomes in older patients. J Am Coll Surg 2010;210:901-908.

19 Revenig LM, Canter DJ, Taylor MD, Tai C, Sweeney JF, Sarmiento JM, Kooby DA, Maithel SK, Master VA, Ogan K: Too frail for surgery? Initial results of a large multidisciplinary prospective study examining preoperative variables predictive of poor surgical outcomes. J Am Coll Surg 2013;217:665-670.e661.

20 Tan KY, Kawamura YJ, Tokomitsu A, Tang T: Assessment for frailty is useful for predicting morbidity in elderly patients undergoing colorectal cancer resection whose comorbidities are already optimized. Am J Surg 2012;204:139-143.

21 Kristjansson SR, Nesbakken A, Jordhoy MS, Skovlund E, Audisio RA, Johannessen HO, Bakka A, Wyller TB: Comprehensive geriatric assessment can predict complications in elderly patients after elective surgery for colorectal cancer: a prospective observational cohort study. Crit Rev Oncol Hematol 2010;76:208-217.

22 Kim YW, Kim IY: Factors associated with postoperative complications and 1-year mortality after surgery for colorectal cancer in octogenarians and nonagenarians. Clin Interv Aging 2016;11:689-697.
23 Huisman MG, van Leeuwen BL, Ugolini G, Montron I, Spiliotis J, Stabilini C, de'Liguori Carino N, Farinella E, de Bock GH, Audisio RA: 'Timed Up \& Go': screening tool for predicting 30-day morbidity in onco-geriatric surgical patients? A multicenter cohort study. PloS One 2014;9:e86863.

24 Audisio RA, Pope D, Ramesh HS, Gennari R, van Leeuwen BL, West C, Corsini G, Maffezzini M, Hoekstra HJ, Mobarak D, Bozzetti F, Colledan M, Wildiers H, Stotter A, Capewell A, Marshall E: Shall we operate? Preoperative assessment in elderly cancer patients (PACE) can help. A SIOG surgical task force prospective study. Crit Rev Oncol Hematol 2008;65:156-163.

25 Huisman MG, Audisio RA, Ugolini G, Montroni I, Vigano A, Spiliotis J, Stabilini C, de Liguori Carino N, Farinella E, Stanojevic G, Veering BT, Reed MW, Somasundar PS, de Bock GH, van Leeuwen BL: Screening for predictors of adverse outcome in onco-geriatric surgical patients: a multicenter prospective cohort study. Eur J Surg Oncol 2015;41:844-851.

26 Kim KI, Park KH, Koo KH, Han HS, Kim CH: Comprehensive geriatric assessment can predict postoperative morbidity and mortality in elderly patients undergoing elective surgery. Arch Gerontol Geriatr 2013;56: 507-512.

27 Huisman MG, Kok M, de Bock GH, van Leeuwen BL: Delivering tailored surgery to older cancer patients: preoperative geriatric assessment domains and screening tools - a systematic review of systematic reviews. Eur J Surg Oncol 2017;43:1-14.

28 Lee YH, Oh HK, Kim DW, Ihn MH, Kim JH, Son IT Kang SI, Kim GI, Ahn S, Kang SB: Use of a Comprehensive Geriatric Assessment to predict short-term postoperative outcome in elderly patients with colorectal cancer. Ann Coloproctol 2016;32:161-169.

29 Ghignone F, van Leeuwen BL, Montroni I, Huisman MG, Somasundar P, Cheung KL, Audisio RA, Ugolini G: The assessment and management of older cancer patients: a SIOG surgical task force survey on surgeons' attitudes. Eur J Surg Oncol 2016;42:297-302.

30 Moyes LH, McCaffer CJ, Carter RC, Fullarton GM, Mackay CK, Forshaw MJ: Cardiopulmonary exercise testing as a predictor of complications in oesophagogastric cancer surgery. Ann R Coll Surg Engl 2013;95:125-130.

31 Yanni F, Moyes LH, McCaffer CJ, Carter RC: Cardiopulmonary exercise testing as a predictor of complications. Ann R Coll Surg Engl 2014;96:86.

32 Chandrabalan VV, McMillan DC, Carter R, Kinsella J, McKay CJ, Carter CR, Dickson EJ: Pre-operative cardiopulmonary exercise testing predicts adverse postoperative events and non-progression to adjuvant therapy after major pancreatic surgery. HPB (Oxford) 2013;15:899-907. 
33 Silver JK, Baima J, Mayer RS: Impairment-driven cancer rehabilitation: an essential component of quality care and survivorship. CA Cancer J Clin 2013;63:295-317.

34 Silver JK, Baima J, Newman R, Galantino ML, Shockney LD: Cancer rehabilitation may improve function in survivors and decrease the economic burden of cancer to individuals and society. Work 2013;46:455-472.

35 Birnstein E, Schattner M: Nutritional support in esophagogastric cancers. Surg Oncol Clin N Am 2017;26:325-333.

36 Looijaard SM, Slee-Valentijn MS, Otten RH, Maier AB: Physical and nutritional prehabilitation in older patients with colorectal carcinoma: a systematic review. J Geriatr Phys Ther 2017;DOI: 10.1519/JPT.0000000000000125.

37 Noh GT, Han J, Cho MS, Hur H, Min BS, Lee KY, Kim NK: Impact of the prognostic nutritional index on the recovery and long-term oncologic outcome of patients with colorectal cancer. J Cancer Res Clin Oncol 2017;143:1235-1242.

38 Leung JS, Seto A, Li GK: Association between preoperative nutritional status and postoperative outcome in head and neck cancer patients. Nutr Cancer 2017;69:464-469.

39 Audisio RA, Balch CM: Why can't surgeons treat older patients the same as younger patients? Ann Surg Oncol 2016;23:4123-4125.

40 Neuman HB, O'Connor ES, Weiss J, Loconte NK, Greenblatt DY, Greenberg CC, Smith MA: Surgical treatment of colon cancer in patients aged 80 years and older analysis of 31,574 patients in the SEER-Medicare database. Cancer 2013;119:639-647.

41 Nagtegaal ID: Never too old to fight cancer? What do we know about colorectal cancer in the elderly? Colorectal Dis 2017;19:223.

42 Fults DW, Taussky P: The life of Rudolf Nissen: advancing surgery through science and principle. World J Surg 2011;35:1402-1408. 